\title{
Reprogramming of RNA silencing triggered by cucumber mosaic virus infection in Arabidopsis
}

\author{
Maria Luz Annacondia and German Martinez ${ }^{*}$ (D)
}

\author{
* Correspondence: german.martinez. \\ arias@slu.se \\ Department of Plant Biology, \\ Uppsala BioCenter, Swedish \\ University of Agricultural Sciences \\ and Linnean Center for Plant \\ Biology, Uppsala, Sweden
}

\begin{abstract}
Background: RNA silencing has an important role mediating sequence-specific virus resistance in plants. The complex interaction of viruses with RNA silencing involves the loading of viral small interfering RNAs (vsiRNAs) into its host ARGONAUTE (AGO) proteins. As a side effect of their antiviral activity, vsiRNAs loading into AGO proteins can also mediate the silencing of endogenous genes. Here, we analyze at the genome-wide level both aspects of the interference of cucumber mosaic virus (CMV) with the RNA silencing machinery of Arabidopsis thaliana.

Results: We observe CMV-derived vsiRNAs affect the levels of endogenous sRNA classes. Furthermore, we analyze the incorporation of vsiRNAs into AGO proteins with a described antiviral role and the viral suppressor of RNA silencing (VSR) 2b, by combining protein immunoprecipitation with sRNA high-throughput sequencing. Interestingly, vsiRNAs represent a substantial percentage of AGO-loaded sRNAs and displace other endogenous sRNAs. As a countermeasure, the VSR $2 b$ loaded vsiRNAs and mRNA-derived siRNAs, which affect the expression of the genes they derive from. Additionally, we analyze how vsiRNAs incorporate into the endogenous RNA silencing pathways by exploring their target mRNAs using parallel analysis of RNA end (PARE) sequencing, which allow us to identify vsiRNA-targeted genes genomewide.
\end{abstract}

Conclusions: This work exemplifies the complex relationship of RNA viruses with the endogenous RNA silencing machinery and the multiple aspects of virus resistance and virulence that this interaction induces.

Keywords: RNA silencing, Virus, Argonaute, Immunoprecipitation, Cucumber mosaic virus

(c) The Author(s). 2021 Open Access This article is licensed under a Creative Commons Attribution 4.0 International License, which permits use, sharing, adaptation, distribution and reproduction in any medium or format, as long as you give appropriate credit to the original author(s) and the source, provide a link to the Creative Commons licence, and indicate if changes were made. The images or other third party material in this article are included in the article's Creative Commons licence, unless indicated otherwise in a credit line to the material. If material is not included in the article's Creative Commons licence and your intended use is not permitted by statutory regulation or exceeds the permitted use, you will need to obtain permission directly from the copyright holder. To view a copy of this licence, visit http://creativecommons.org/licenses/by/4.0/. The Creative Commons Public Domain Dedication waiver (http://creativecommons.org/publicdomain/zero/1.0/) applies to the data made available in this article, unless otherwise stated in a credit line to the data. 


\section{Background}

The development and survival of plants depend on their ability to adapt to the surrounding environmental conditions, which can be beneficial or harmful. Changes in the surrounding environment of plants can occur suddenly; hence, plants rely on the plasticity of their genome to cope with these disturbances [1-3]. One of the genetic tools that helps plants to cope with stress is an adaptive and highly specific mechanism to regulate gene expression, termed RNA interference (RNAi) or RNA silencing $[4,5]$. Briefly, this mechanism is triggered by the presence of a double-stranded RNA (dsRNA), which is cleaved by Dicer-like (DCL) proteins to produce small interfering RNAs (siRNAs), typically of 21- to 24-nt long. One strand of these siRNAs is then loaded into ARGONAUTE (AGO) proteins forming the RNA-induced silencing complex (RISC) to lead the posttranscriptional gene silencing (PTGS) or transcriptional gene silencing (TGS) of the target RNA [6]. siRNAs can initiate the amplification of the RNA silencing signal inducing the biogenesis of additional siRNAs termed secondary [7].

Viruses are an especially interesting group of pathogens as they entirely depend on their hosts to complete their life cycle [8]. Plants use the RNA silencing machinery as an antiviral strategy that provides sequence specificity against viruses $[9,10]$. Once the virus has entered into the cell, dsRNAs produced from different sources, such as the viral genome, in the case of RNA viruses, or the transcripts produced by the viral genome, in the case of DNA viruses, trigger the activation of the RNA silencing pathway [6]. Then, DCL proteins process these dsRNAs into viral-derived small interfering RNAs (vsiRNAs), which are mainly 21-nt long and produced by DCL4 [6, 11, 12] or 22-nt long and produced by DCL2 [12-14] and immunize cells against the viral infection. Further evidence of the important role of RNA silencing as an antiviral mechanism is that to counteract this defense mechanism, viruses have developed proteins termed viral suppressors of RNA silencing (VSRs) $[15,16]$. VSRs from different viruses can suppress the host RNA silencing activity at different steps of the pathway [15-17]. A common strategy, followed by multiple viruses, is the VRS-mediated sequestering of vsiRNAs to avoid the targeting of the viral genome by AGO proteins $[15,16]$. This strategy is used by two of the most studied VSRs: the Tombusvirus P19 and the Cucumovirus 2b proteins. P19 is capable of binding vsiRNAs to avoid the antiviral activity of the RNA silencing pathway $[18,19]$. Furthermore, P19 can bind endogenous sRNAs like the microRNA (miRNA) miR168, which modulates AGO1 mRNA levels during viral infection [19]. 2b loads vsiRNAs to prevent the RNA silencing signal spreading and, ultimately, the silencing of the viral genome [20]. Additionally, $2 \mathrm{~b}$ can inhibit PTGS and TGS by interfering with the function of AGOs by blocking AGO1 cleavage activity and, therefore, inhibit miRNA pathways [21], and by directly interacting with AGO4 and interfering with the RNA-directed DNA methylation pathway [20]. These proteins exemplify the duality of the interaction of viruses with the RNA silencing machinery, which is used by the host to control viral accumulation, but can also be used by the virus to regulate host processes.

In the last years, this dual interaction with the RNA silencing pathway has been studied in several host/parasite interactions. A common theme for many pathogens is the development of an alternative interaction with the host RNA silencing machinery that allows them to target host endogenous genes. Examples of this side-effect been 
described in different types of pathogens, such as parasitic plants, fungi, viruses, or viroids [22-25] and endogenous genomic parasites such as transposable elements [26]. For instance, the parasitic plant Cuscuta campestris produces 22-nt miRNAs that target Arabidopsis thaliana genes during their parasitic interaction, causing a decrease on the expression of host genes, such as auxin receptors or phloem proteins, among others [22]. Moreover, the fungal pathogen Botrytis cinerea produces sRNAs that target Arabidopsis genes related to plant immunity, such as MITOGEN-ACTIVATED PROTEIN KINASE 1 and 2 (MPK1 and MPK2); PEROXIREDOXIN IIF (PRXIIF), a gene involved in oxidative stress; and CELL WALL-ASSOCIATED KINASE (WAK), by binding to the host AGO1 [23]. In the case of viruses and viroids, they use the vsiRNAs (vdsiRNAS for viroids) generated by the RNA silencing pathway on their own benefit by targeting host genes [24, 25, 27, 28]. This is the case of CMV Y-satellite RNA (Y-Sat), a small parasitic RNA that accompanies CMV and produces vsiRNAs that can target and downregulate a Nicotiana benthamiana gene involved in chlorophyll biosynthesis (I subunit of Mg-chelatase, CHLI) [24, 27]. Notably, although selected examples of genes targeted by vsiRNAs have been described, the genome-wide effects of vsiRNAs on host gene expression have not been characterized yet.

To shed light into that, here, we analyzed the interference of CMV with the RNA silencing pathways of Arabidopsis thaliana. To this aim, we studied the viral and endogenous sRNA populations in CMV-infected Arabidopsis plants, their loading into the main antiviral AGOs (AGO1, AGO2, AGO5, and AGO7) and the CMV VSR protein $2 \mathrm{~b}$, and the vsiRNA-targeted genes by means of parallel analysis of RNA ends (PARE). Our analysis revealed that the loading of vsiRNAs into AGO proteins displaced host endogenous sRNAs but also that vsiRNAs targeted a myriad of endogenous genes, mainly photosynthesis-related. Furthermore, $2 \mathrm{~b}$ loaded vsiRNAs together with host mRNA-derived sRNAs which might interfere with the transcriptional regulation of their mRNAs of origin. In summary, our study provides a complete analysis of the interaction of a viral infection with the host RNA silencing machinery and sheds light into the multiple aspects of RNA silencing affected by RNA pathogens.

\section{Results}

\section{CMV infection disrupts the Arabidopsis endogenous sRNA populations}

To understand how sRNA populations are affected during CMV infection in Arabidopsis, we produced and sequenced sRNA high-throughput libraries of both mock and CMV Fny-inoculated rosette leaves at 30 dpi (Additional file 1: Table S1 and Fig. 1A). As previously described, vsiRNAs accumulated to high levels in CMV-infected tissues [29], comparable to endogenous miRNAs with high accumulation levels like miR168 (Fig. 1B). The analysis of our sRNA data identified that in our libraries vsiRNAs represented almost half (43.1\%) of the total pool of sRNAs that were sequenced, being the rest derived from the Arabidopsis genome (56.9\%) (Fig. 1C). This considerable population of vsiRNAs was mainly constituted by vsiRNAs that were 21-nucleotide (nt) long (70.2\%), followed by 22-nt (18.14\%) and 20nt vsiRNAs (7.5\%), as it was previously reported for RNA viruses in different studies [29-31] (Fig. 1D). Moreover, vsiRNAs were produced from the three genomic RNAs that constitute the CMV genome, predominantly from RNA 2 (42.94\%) and 


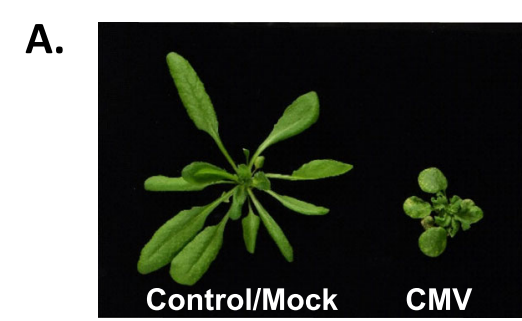

D.

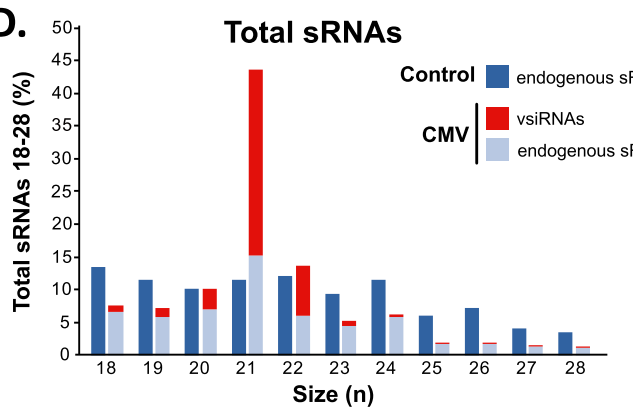

F.

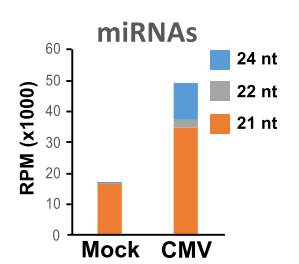

G.

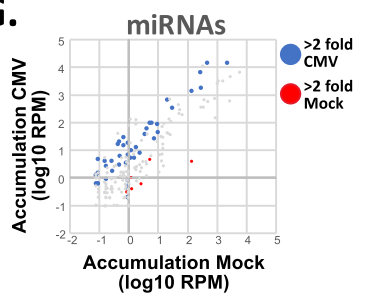

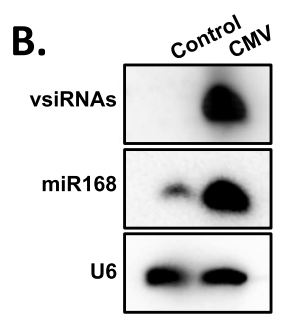

C. Total sRNAs CMV infected
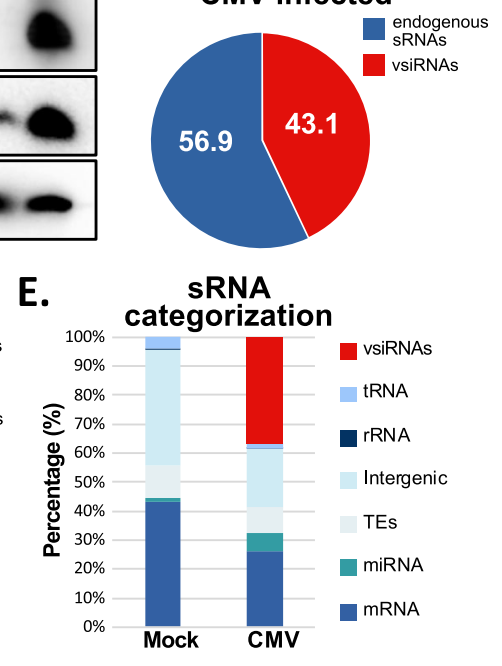

Fig. 1 CMV-derived sRNAs affect endogenous sRNA proportions. A Representative pictures of mock and CMV-infected Arabidopsis Col-0 at 20 dpi. B Northern blot detection of vsiRNAs, miR168, and U6. U6 was used as a loading control. $20 \mathrm{\mu g}$ of total RNA was loaded on each lane. C Proportion of CMV sRNAs vs endogenous Arabidopsis sRNAs in CMV-infected sRNA libraries. D Size distribution of the whole mapped sRNAs for mock and CMV-infected libraries. E Categorization in different classes of sRNA for mock and CMVinfected samples. F Proportion of 21-, 22-, and 24-nt sRNAs mapping to miRNAs, TEs, and mRNAs in mock and CMV-infected samples. G Scatterplot of sRNA accumulation (log10 of RPMs) for individual miRNA families, TEs, and mRNAs. Elements that accumulate 2-fold or higher sRNAs in CMV samples are highlighted in blue while elements that accumulate 2-fold or higher in mock samples are highlighted in red. Two bioreplicates from sRNA libraries were generated and analyzed

RNA 3 (41.94\%), with a lower proportion coming from RNA 1 (15.11\%) (Additional file 2: Fig. S1A-B). This proportion of vsiRNAs from the different genomic RNAs at our sampling time (30 dpi) was confirmed by Northern blot (Additional file 2: Fig. S1C). Interestingly, vsiRNAs followed a different dynamic of accumulation than genomic RNAs, which were relatively stable at 10,20 , and 30 dpi (Additional file 2: Fig. S1C). This difference of accumulation between genomic and siRNAs from CMV probably is due to the effect of RDR-mediated amplification of the RNA silencing signal [14, 32] as previously reported for CMV [33]. Next, to understand how vsiRNAs affected the different endogenous sRNA 
populations, we analyzed the proportion of different classes of sRNAs in both mock and CMV-infected sRNA libraries (Fig. 1E and Additional file 2: Fig. S2). In general, infection led to a general reduction in the accumulation of endogenous sRNAs, with the exception of miRNAs, which increased their accumulation (Fig. 1E). We further confirmed this higher accumulation levels for miR168 by Northern blot (increased more than 32-fold in CMV libraries, as previously described [21, 34], Fig. 1B). A detailed analysis of sRNA profiles showed that together with miRNAs, 21-nt sRNAs derived from mRNAs and TEs also increased their accumulation in infected tissues (Fig. 1F and Additional file 2: Fig. S2). 22.3\% of miRNA families accumulated to higher level under CMV infection ( $>2$ fold with $p$ value $<0.05$ ), including important developmental regulators like miR158, miR172, or miR393 (Fig. $1 \mathrm{G}$ and Additional file 1: Table S2). On the other hand, $6.8 \%$ and $6.7 \%$ of mRNAs and TEs, respectively, produced increased amount of 21-nt sRNAs under CMV infection ( $>2$ fold with $p$ value $<0.05$, Fig. $1 \mathrm{G}$ and Additional file 1: Table S3 and Additional file 1: Table S4). TEs producing 21-nt sRNAs during CMV infection were significantly enriched in members of the Gypsy superfamily and depleted in members of the DNA superfamily (Additional file 2: Fig. S3A). Gypsy members occupy heterochromatic regions in the Arabidopsis genome [35], and, in line with the enrichment of this class of TEs, TEs producing a higher amount of 21-nt sRNAs during CMV infection had heterochromatic features including significant higher values of DNA methylation, size, and of the heterochromatic histone modification H3K9me2 (Additional file 2: Fig. S3B-D). This higher accumulation of 21-nt sRNAs might be due to their transcriptional reactivation, since 24-nt TE-derived sRNAs were reduced during CMV infection (Additional file 2: Fig. S2D). Additionally, the production of 21-nt TE-derived sRNAs could be attributed to the activity of the VSR of CMV, 2b, since the increased production of TE-derived sRNAs during CMV infection was absent in data obtained from Arabidopsis plants infected with the CMV- $\Delta 2 \mathrm{~b}$ strain $[33,36]$, which lacks the $2 \mathrm{~b}$ protein (Additional file 2: Fig. S3E). Altogether, these results showed that vsiRNAs derived from CMV were produced from all its genome entirety, were mainly 21-nt long, and potentially affected the proportion of endogenous sRNA populations due to their relative high accumulation levels.

\section{Global AGO sRNA-loading is affected by vsiRNAs}

To better understand the potential hijacking of the host RNA silencing machinery caused by vsiRNAs, we studied the interaction of vsiRNAs with the host AGO proteins, the key effectors of the antiviral pathway. Since AGO proteins load sRNAs with a preference for certain $5^{\prime}$ nucleotides [37], we initially inferred the potential preference of vsiRNAs by analyzing their $5^{\prime}$ nucleotide prevalence in our sRNA sequencing data (Fig. 2A). 21 and 22-nt vsiRNAs had a similar 5' nucleotide distribution with $\mathrm{U}$ being the main $5^{\prime}$ nucleotide (31.8 and $31.4 \%$, respectively) followed by A (26.6 and $24.3 \%$ ), C (23.7 and $25.8 \%$ ), and G (17.8 and 18.3\%), indicating a preference for a loading into AGO1, AGO2, and AGO5 [37]. In line with their previously described antiviral role, mutants in AGO1, AGO2, and AGO5 were significantly susceptible to CMV Fny infection compared to mock plants (Fig. 2B and Additional file 2: Fig S4A), while AGO7 


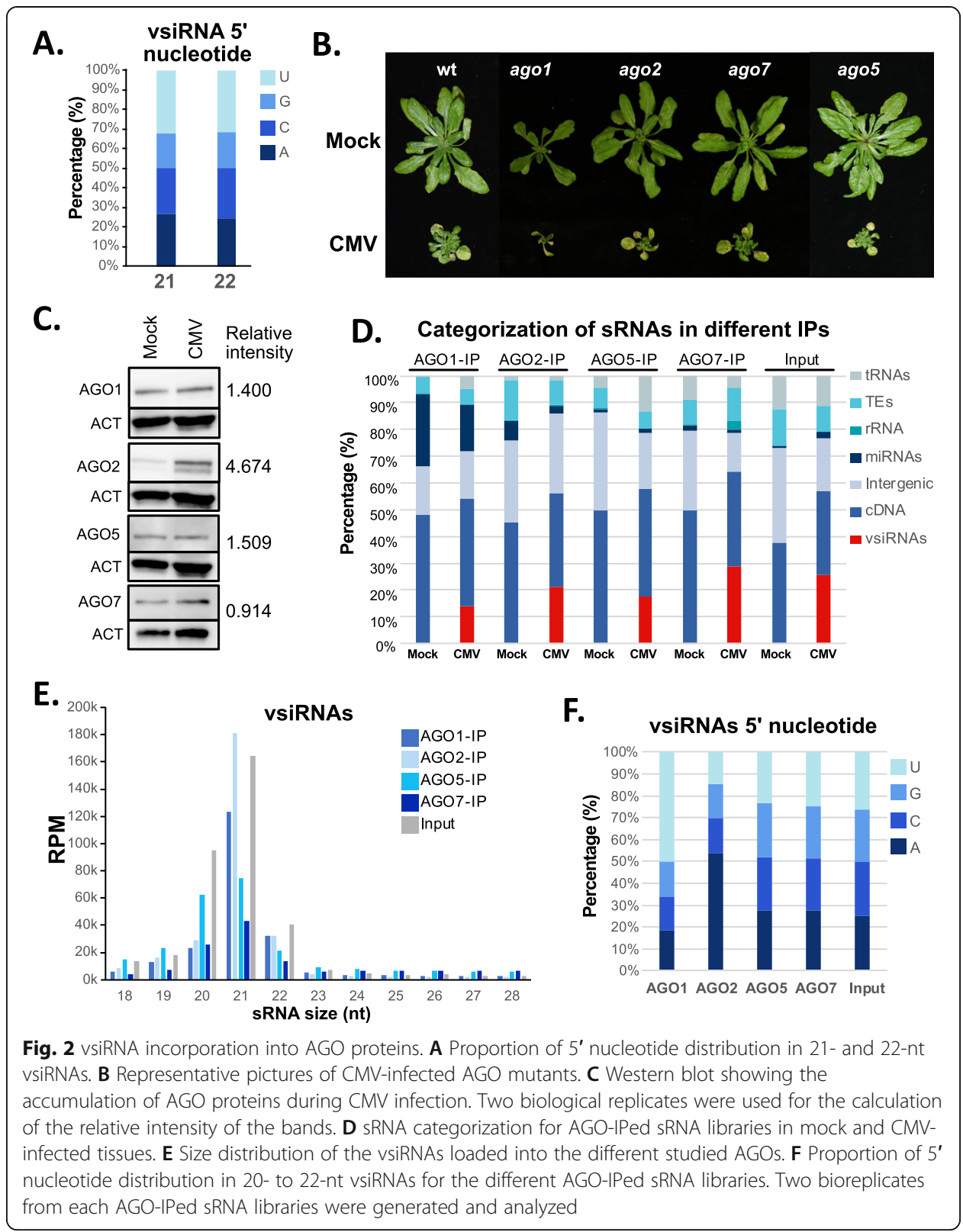

mutants were slightly resistant to the infection (Additional file 2: Fig S4A). During CMV infection, all the AGO proteins analyzed, but AGO7, increased their accumulation, especially AGO2 (4.6 fold increase relative to mock (Fig. $2 \mathrm{C}$ and Additional file 2: Fig S4B) as previously described [38].

Next, we analyzed the characteristics and disturbance of sRNA loading into AGO proteins during CMV infection. To that end, we performed AGO immunoprecipitation (IP) followed by sRNA high-throughput sequencing for AGO1, AGO2, AGO5, and AGO7 (all of which have been showed to have an antiviral role) [4, 11,38, 39], in mock- and CMV-inoculated plants using commercial antibodies for AGO1, AGO2, and AGO5 and an AGO7-HA tagged transgenic line (AGO7:HA-AGO7) transformed in an ago7 mutant [40]. Our AGO-IP analysis showed interesting characteristics of AGO behavior during viral infection (Fig. 2D). First, CMV infection induced vsiRNA loading in 
all AGO analyzed (Fig. 2D). In terms of total AGO sRNA proportion, vsiRNAs occupied mainly AGO7 (28.9\%), AGO2 (21.3\%), AGO5 (17.7\%), and AGO1 (13.9\%) (Fig. 2D). vsiRNAs loaded into AGO proteins were mainly on 21-nt in AGO1 and AGO2 (56.3 and $64.2 \%$ of all 18- to 28-nt vsiRNAs, Fig. 2E), while AGO5 and AGO7 loaded both 20 - and 21-nt vsiRNAs (26.1/31.2\% and 19.4/32.4\% of 20/21-nt sRNAs, Fig. 2E). Interestingly, the overall input vsiRNA profile (normalized to reads per million, RPM) presented prominent peaks of 20- and 21-nt length, resembling a compromise between both AGO1 and AGO2 21-nt and AGO5 and AGO7 20-/21-nt preferential vsiRNA loading (Fig. 2E). AGO2 and AGO1 were the AGO proteins with the higher vsiRNA loading, as expected, while AGO5 and AGO7 had a secondary role in the antiviral response (Fig. 2E), similar to the role of AGOs during Turnip mosaic virus infection (TuMV) in N. benthamiana [4]. vsiRNAs loaded into different AGOs presented the expected 5' nucleotide preference previously described in Arabidopsis [37], with AGO1 loading 57.5\% and AGO2 loading 60\% of $\mathrm{U}$ and A 5 '-nucleotide terminal 20-22-nt vsiRNAs, respectively (Fig. 2F). In parallel to vsiRNA loading, other sRNA categories decreased their AGO occupancy, specially miRNAs in AGO1, AGO2, and AGO7 (1.5-, 2.6-, and 2-fold decrease, respectively). Unexpectedly, AGO5 increased the loading of specific miRNA families under CMV infection (global 1.5-fold increase Fig. 2D and Additional file 2: Fig S5). Together with miRNAs, the general trend for the rest of genomic categories was a decrease of their accumulation. This was the case for mRNA-, TE-, and intergenic-derived sRNAs (1.3-, 1.2-, and 1.5-fold decrease on average for the four AGOs under study, Fig. 2D). In summary, CMV infection affected all AGO protein homeostasis, first increasing AGO protein accumulation (except AGO7) but also affecting the sRNA proportions loaded in AGO proteins, which might be displaced by vsiRNA loading.

\section{2b VSR loads 20-21 nt viral and mRNA-derived sRNAs}

CMV VSR, the $2 \mathrm{~b}$ protein, interacts with the RNA silencing pathways by direct loading of vsiRNAs $[20,21]$. Overexpression of the $2 \mathrm{~b}$ protein inhibits siRNA-mediated TGS and PTGS silencing [41-44]. Indeed, we generated $2 \mathrm{~b}$ transgenic plants which confirmed that its overexpression induced a myriad of developmental defects resembling the effects of mutations in key components of the RNA silencing pathways (Fig. 3A). To understand in detail how the $2 \mathrm{~b}$ protein might interact with RNA silencing pathways within the context of CMV infection, we performed an IP of the $2 \mathrm{~b}$ protein using commercial antibodies available (see the "Materials and methods" section for details) followed by generation of sRNA high-throughput libraries from naturally infected tissues. The analysis of the sRNA libraries generated (Additional file 1: Table S1), indicated that $2 \mathrm{~b}$ can bind to all sRNAs categories, with a preference for mRNA-derived sRNAs (1.6-fold increase in 2b-IP samples and $25.2 \%$ of all $2 \mathrm{~b}$-loaded sRNAs, Fig. 3B, C). 2b was also able to load miRNA (Additional file 2: Fig S6), TE-derived sRNAs, and intergenic-derived sRNAs, although these last ones were relatively depleted from the IP (2-fold depletion compared to input samples, Fig. 3B). 2b-loaded mRNA-derived sRNAs corresponded to 2211 mRNAs (5.4\% of all mRNAs, sRNA accumulating equal, or more than 2-fold with a $p$ value inferior to 0.05 , Fig. 3D). We further enquired the potential role of these sRNAs during infection by analyzing mRNA expression under 


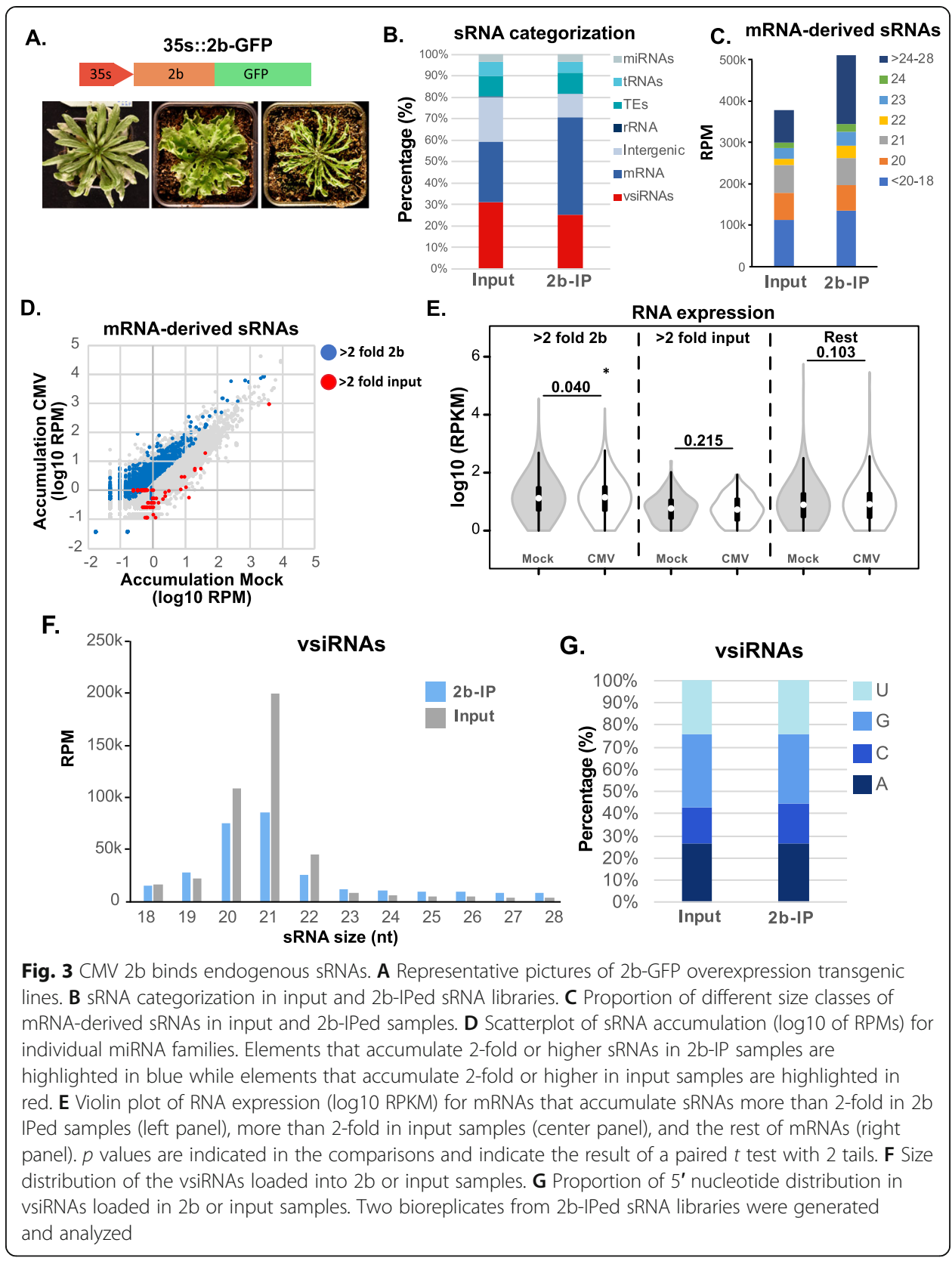

CMV infection, which has been studied previously [45, 46]. Our analysis of public RNA sequencing data [45] indicated that mRNAs that produced sRNAs preferentially incorporated into $2 \mathrm{~b}$, reduced their expression significantly during infection compared to mRNAs that did not incorporate sRNAs into 2b (Fig. 3E). This indicated that the loading of mRNA-derived sRNAs into $2 \mathrm{~b}$ could be involved with their transcriptional regulation during CMV infection.

vsiRNAs followed mRNA-derived sRNAs as preferentially loaded sRNAs $(25.2 \%$ of all 2b-loaded sRNAs, Fig. 3B and Additional file 2: Fig S6). 2b-loaded vsiRNAs are of 20- and 21-nt, similar to the overall vsiRNAs present in input samples (Fig. $3 \mathrm{~B}-\mathrm{F}$ and Fig. 2E). This indicated that $2 \mathrm{~b}$-loaded vsiRNAs are an important part of the overall vsiRNA population accumulating during infection. Contrary to AGO 
proteins, $2 \mathrm{~b}$ did not present a clear $5^{\prime}$ nucleotide preference in the vsiRNAs that it is capable of loading (Fig. 3G). Thus, CMV VSR, 2b, had an active role during viral infection both loading mRNA-derived sRNAs, with a potential transcriptional regulation role, and vsiRNAs.

\section{vsiRNAs target endogenous genes associated with photosynthesis, generation of metabolites, and translation}

Our data indicated that vsiRNAs were incorporated into all the AGOs analyzed, representing a substantial portion of the immunoprecipitated sRNAs. To further understand if these vsiRNAs could be actively incorporated into the endogenous RNA silencing machinery and target host mRNAs, we performed PARE sequencing of CMVinoculated tissues (Figs. 1A and 4A, B). The analysis of these libraries using PAREsnip

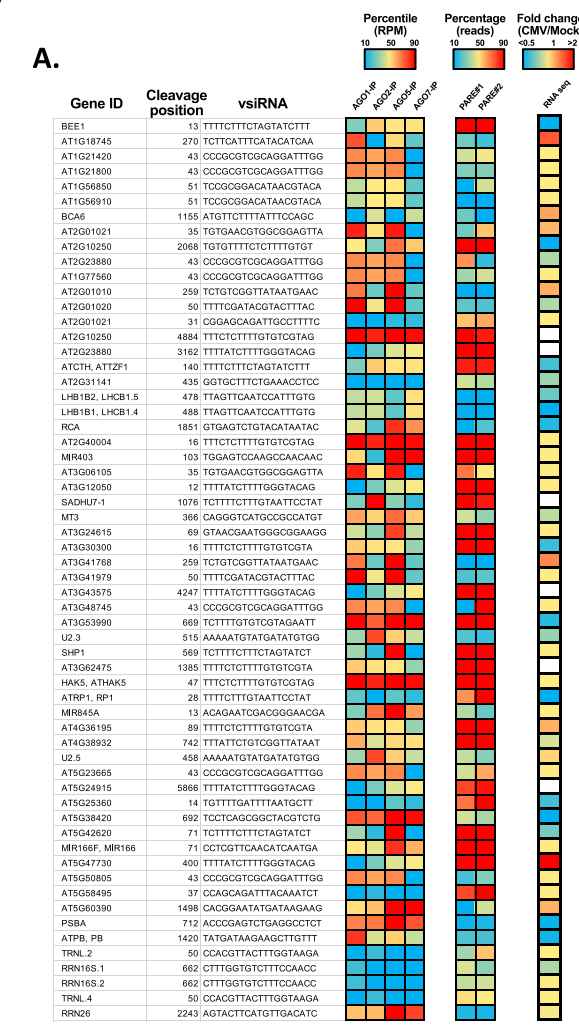

B.
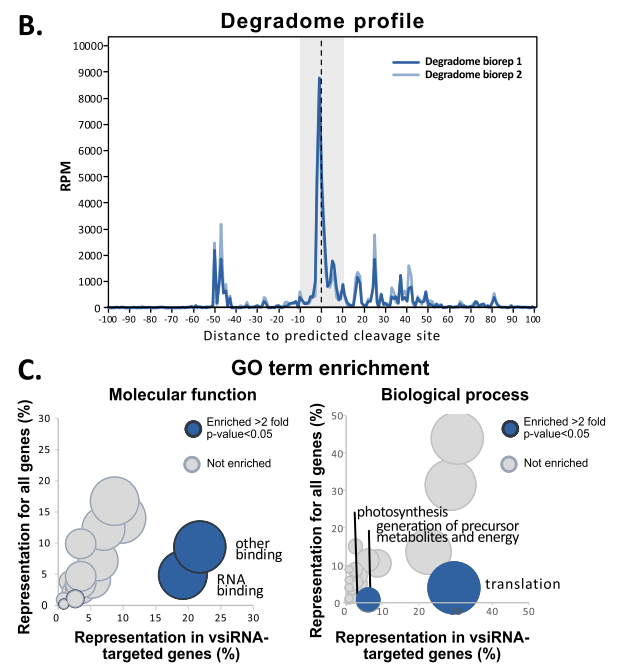

GO term enrichment

D. vsiRNA-targeted
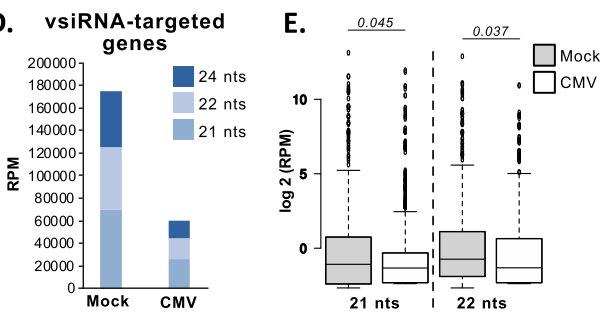

Fig. 4 Analysis of vsiRNA-targeted RNAs. A Table of the genes targeted by vsiRNAs showing their gene ID, cleavage position, vsiRNA targeting, the level of their presence in different AGO IPs (showed as a heat map for their RPM accumulation), the accumulation of PARE reads in the predicted cleavage position (showed as a heat map for the percentage of reads from the specific mRNA that map to the cleavage position), and the fold change of mRNA expression under CMV infection (showed as a heat map of the fold change of mRNA expression in CMV vs mock). B PARE read profile relative to the predicted cleavage position identified by PAREsnip. C Analysis of GO term enrichment. Left panel shows the analysis according to molecular function and right panel shows the analysis for biological process. Blue-colored dots show categories enriched equal or more than 2-fold with a $p$ value inferior to 0.05. D Proportion of 21-, 22-, and 24-nt sRNAs derived from vsiRNA-targeted genes in mock and CMV-infected sRNA libraries. E Box-plot representing the accumulation (log2 RPM) of 21- and 22-nt sRNAs derived from individual mRNAs in mock and CMV-infected sRNA libraries. Whiskers extend to data points that are less than $1.5 \times$ IQR away from 1st/ 3rd quartile. $p$ values are indicated in the comparisons and indicate the result of a paired $t$ test with 2 tails. Two bioreplicates from PARE RNA libraries were generated and analyzed 
[47] identified 61 endogenous mRNAs with evidences of vsiRNA-induced cleavage (targets confirmed in both bioreplicates using astringent PAREsnip parameters, Fig. 4A, B and Additional file 1: Table S5). vsiRNAs that were predicted to target genes were loaded in all the AGOs analyzed with a slight preference for AGO5 loading (Fig. 4A-left column and Additional file 2: Fig S7). As expected from real vsiRNA targets, these mRNAs presented a read peak mapping to the predicted cleavage position of the vsiRNA in the mRNA sequenced (Fig. 4B), which in some cases accounted to up the majority of PARE reads mapping to the predicted target (Fig. 4A, middle column). Together with this, some vsiRNA-targeted mRNAs reduced their accumulation during CMV infection in RNA sequencing datasets from public repositories [45], pointing to an effect in the accumulation of the targeted mRNAs (Fig. 4A, right column).

To further characterize the vsiRNA-targeted mRNAs, we analyzed the Gene Ontology (GO) term enrichment according to molecular function. Interestingly, vsiRNA-targeted mRNAs had an enrichment ( $>2$ fold and $p$ value $<0.05$ calculated through a Fisher's exact test) in GO categories related to nucleic acid binding, such as RNA binding and other binding (Fig. 4C left panel). The same analysis performed for GO terms according to biological function highlighted a significant enrichment ( $>2$ fold and $p$ value $<0.05$ calculated through a Fisher's exact test) in genes associated with photosynthesis, translation, and generation of precursor metabolites and energy (Fig. 4C right panel). These target genes included two photosystem II light harvesting complex LHCB1.4 and LHCB1.5, and the tandem zinc finger protein (ATCTH), all well-characterized mediators of the photosynthesis and translation processes, respectively (Fig. 4A) [48-50]. Interestingly, CMV-derived sRNAs have been previously associated with the downregulation of photosynthesis associated genes in $N$. benthamiana $[27,51]$

Finally, we analyzed if vsiRNA-mediated cleavage induced the initiation of the RNA silencing amplification of their mRNA targets [52]. To that end, we analyzed the proportion of 21-, 22-, and 24-nt mRNA-derived sRNAs in mock and CMV-infected highthroughput sRNA libraries (Fig. 4D). In general, vsiRNA-targeted mRNAs did not produce higher levels of sRNAs, as it would be expected of a canonical secondary siRNA biogenesis pathway (Fig. 4D). Indeed, 21- and 22-nt mRNA-derived sRNAs from vsiRNA targets are significantly decreased in CMV-infected sRNA libraries (Fig. 4E). In sum, vsiRNAs were incorporated into the canonical RNA silencing pathways and were active regulators of endogenous mRNAs.

\section{Validation of vsiRNA biological activity}

As a proof of concept on the ability of vsiRNAs to target mRNAs, we selected two candidate genes: AT4G21210 (RP1) a chloroplastic pyruvate orthophosphate dikinase (PPDK) regulatory protein with a known role in photosynthesis [53, 54], and AT4G36195, a serine carboxypeptidase S28 family protein (Figs. 4A and 5A and Additional file 2: Fig S8A). These two genes were targeted by two vsiRNAs that accumulate preferentially in AGO2 and AGO1, respectively (Additional file 2: Fig S8C and D), and had a clear PARE read peak at their predicted cleavage position (Fig. 5A and Additional file 2: Fig S8A). In accordance with our preliminary analysis, the expression of both genes (analyzed by RT-qPCR) was significantly downregulated in plants infected with CMV (Additional file 2: Fig S8E). Next, to determine that this 


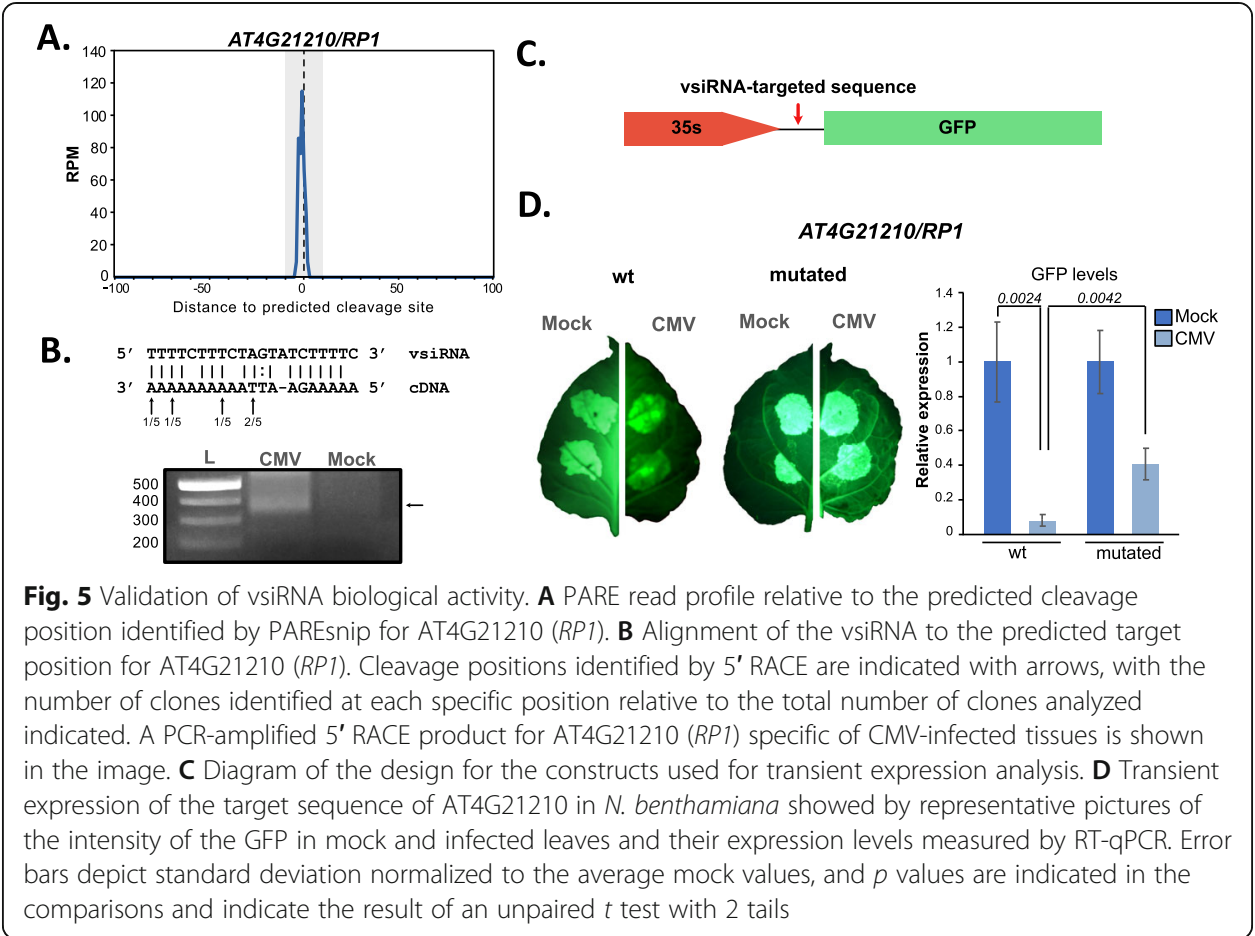

downregulation takes place specifically due to the activity of vsiRNAs, we performed a transient expression assay in N. benthamiana (Fig. 5D and Additional file 2: Fig S8B). To that aim, we generated two constructs each one containing the vsiRNA-targeted sequence from the two selected candidate genes, driven by the $35 \mathrm{~S}$ promoter and located in the 5'UTR of the GFP sequence, which allowed us to both visualize the expression of this transgene and to quantify its accumulation levels (Fig. 5C). These constructs were then agroinfiltrated in both mock and 7 dpi CMV-infected N. benthamiana leaves, and the level of accumulation of GFP transcripts was monitored by RT-qPCR (Fig. 5D and Additional file 2: Fig S8B). These analyses indicated that the expression of both constructs was significantly downregulated in the infected plants indicating that the downregulation of both genes is associated with the presence of the region targeted by vsiRNAs (Fig. 5D and Additional file 2: Fig S8B). Furthermore, this downregulation was partially alleviated in both constructs when the vsiRNA-targeted site was mutated in 4 positions [55] to affect the binding of the vsiRNAs (Fig. 5D and Additional file 2: Fig S8B). Nevertheless, the introduction of these mutations did not return expression of the construct to wild type levels, which might be due to vsiRNAs still retaining some binding ability to the target site, as observed in Liu et al. (2014) when comparing 4, 5, and 6 mismatches in the $5^{\prime}$ seed of a miRNA binding site [55]. We additionally confirmed the targeting of $R P 1$ by its corresponding vsiRNA by modified 5'RACE [56], which confirmed the targeting position identified by PARE sequencing (Fig. 5B). In summary, these results proved the ability of vsiRNAs to target plant genes and effectively decrease their expression. 


\section{Discussion}

RNA silencing plays a fundamental role in the defense response to viruses due to their obligate intracellular nature [57]. Even though the characteristics of this pathway have been widely studied since it was first described $[58,59]$, there are still some aspects that remain poorly understood. Here, we have studied a less known aspect of this pathway, the overall interference with the endogenous RNA silencing machinery, via the sequencing of viral and endogenous sRNAs, the analysis of vsiRNA incorporation into different AGO proteins and the identification of endogenous mRNAs targeted by vsiRNAs. Moreover, we have characterized the sRNAs bound to the VSR of CMV, the 2b protein. Altogether, our data provides a complete portrait of this complex plant-pathogen interaction.

The effects of CMV infection on the endogenous sRNA populations had been previously described only for the VSR-deficient mutant of CMV and CMV- $\Delta 2 \mathrm{~b}$, which induces the production of RDR1-dependent virus-activated siRNAs (vasiRNAs) that target thousands of endogenous loci [36]. Other previous studies focused on the characterization of the vsiRNAs generated from the genome of CMV $[29,60]$ or its satellite RNA [61, 62], similar to studies in other plant viruses and pathogenic RNAs [29, 31, 63, 64]. In our work, we have studied the changes experienced by the endogenous Arabidopsis sRNA populations under the infection by the CMV strain Fny, which is symptomatic in Arabidopsis and other hosts [65-67]. We observed that endogenous sRNA populations were strongly affected by the massive accumulation of vsiRNAs, which accounted to more than $43 \%$ of all the sRNA reads in infected tissues. Although the level of accumulation of viral genomes per cell for CMV is unknown (a parameter known as cellular multiplicity of infection or MOI), viruses like Tobacco etch virus (TEV) [68], Tobacco mosaic virus (TMV) [69], or Turnip mosaic virus (TuMV) [70] accumulate 1 to 2 genomes per infected cell at later infection times, with up to 6 genomes per cell [69] and up to $42 \%$ of infected cells [68] at earlier infection times (10 dpi). Our tissues correspond to later infection times (30 dpi) although we did not observe a reduction in the accumulation of viral RNAs by Northern blot (Additional file 2: Fig S1C). Interestingly, CMV vsiRNA accumulation was not correlated with the accumulation of CMV genomic RNAs. This disconnection between viral genomic RNA and vsiRNA accumulation is probably explained by the RDR-mediated amplification of vsiRNAs [14, 32]. The massive amount of vsiRNAs might not only accumulate at infected cells, since the antiviral RNA silencing signal is known to spread both locally [71] and systematically [72] providing immunization of tissues before viral infection.

Our work exemplifies the consequences of using RNA silencing as the main mechanism to provide antiviral immunization in plants. We show that massive vsiRNA accumulation caused a decrease in the presence of almost all sRNA categories. This increased presence of vsiRNA was not only a consequence of their great accumulation in the cytoplasm, since we also identified their loading into the different AGO proteins studied here (AGO1, AGO2, AGO5, and AGO7) indicating their active incorporation into effectors of RNA silencing. Interestingly, all the AGOs studied here showed a similar percentage of vsiRNAs (with AGO7, which has a positive effect against CMV infection, being the AGO protein where vsiRNAs occupied a higher percentage of the 
loaded sRNAs). AGO proteins prefer loading sRNAs with certain $5^{\prime}$ nucleotides [37], but they reflect the population of sRNAs present in their main subcellular niche. For example, AGO1 loads increased amount of epigenetically active siRNAs (easiRNAs) from TEs when heterochromatin is compromised in DECREASE IN DNA METHYLATION 1 (DDM1) mutants [26], or in other examples where the cell is loaded with anomalous proportions of exogenous sRNAs [4,73]. Our work reveals that this is the case for probably all AGO proteins. Additionally, our data indicates that the antiviral roles of AGO1 and AGO2 are probably influenced by their increased accumulation during CMV infection compared to other AGOs (such as AGO5 or AGO7). Epigenetic changes in the $\mathrm{AGO} 2$ promoter region are associated with its increased expression under CMV infection in benzo-(1,2,3)-thiadiazole-7-carbothioic acid $S$-methyl ester (BTH)-primed plants [74]. It is plausible to speculate that the promoter of antiviral (or stress responsive) AGOs are prone to experience epigenetic changes or harbor transcription factor binding sites that enhance their expression during stress. CMV is indeed connected to epigenetic changes through the targeting of 24-nt sRNA characteristic of the RdDM pathway by its VSR $2 b$ [20, 42]. A reduced amount of 24-nt sRNAs will cause a reduction in DNA methylation that might affect the transcription of epigenetically labile regions [75], such as the ones present in the promoter region of AGO2. In line with these potential epigenetic changes, we detected that selected TEs enriched in all contexts of DNA methylation and the repressive histone mark H3K9me2, produced higher levels of 21-nt sRNAs from their transcripts. Furthermore, this increased production of 21-nt sRNAs is associated with the presence of $2 \mathrm{~b}$ in the genome of CMV. It is possible that the production of 21-nt sRNAs from TEs reflects epigenetic changes (both at the DNA methylation and histone levels) under CMV infection, which is known to induce changes in the DNA methylation levels of its host as previously shown in Nicotiana benthamiana [76].

Together with selected TEs, exceptionally, some miRNA families and mRNAs also accumulated higher levels of 21-nt sRNAs. Increased presence of miRNAs might be associated with their loading into AGOs other than AGO1 or the VSR 2b, since we detected an enrichment of certain miRNA families under CMV infection in AGO2-, AGO5-, and 2b-IPed sRNA libraries. It is plausible that AGO2 and AGO5 loading of miRNAs might be a mechanism that compensates the decrease of miRNAs loaded into AGO1. The disruption of the mock profile of miRNAs could be impacting the normal development in CMV-infected plants, as this class of sRNAs play an important role in the regulation of plant development [77]. Indeed, CMV-induced developmental symptoms are conditioned partly by $2 \mathrm{~b}-\mathrm{AGO} 1$ interactions and the consequent interference with miRNA regulated gene expression [43].

To complement the overview of the interaction of CMV with RNA silencing pathways, we further immunoprecipitated and sequenced sRNAs associated with the VSR of CMV, 2b. The previous analysis of the sRNAs associated with $2 \mathrm{~b}$ identified an enrichment of 24 nt sRNAs [20]. In our study, we could not identify any sRNA size class with a preferential enrichment, although we found an enrichment of mRNA-derived siRNAs, pointing to the technical success of the technique. We think that these differences might account for the use of a commercial antibody in our study and also our analysis within the context of a CMV Fny infection, which differs from the wild type scenario of the Hamera et al. (2011) study. mRNA-derived siRNAs enriched in 2b are 
associated with transcripts that decrease their accumulation significantly during CMV infection, pointing to a role of these sRNAs in the regulation of the expression of the genes from which they originate. sRNAs in other species can promote the stability of their target mRNAs [78] and certain mRNAs experiencing translation inhibition mediated by miRNAs decrease their accumulation to enhance the production of their corresponding protein in microRNA action-deficient (MAD) mutants [79]. Further analysis of the connection between transcriptional and translation effects of viral infection are needed to understand the extend of the role of $2 \mathrm{~b}$-sequestered mRNA-derived sRNAs.

Finally, we studied another side effect of antiviral RNA silencing, the ability of vsiRNAs to target endogenous genes. Incorporation of CMV-derived vsiRNAs into RISC complexes indicated that they could potentially target endogenous transcripts. This side effect has been analyzed for several pathogen/parasite-host interaction, where pathogen/parasite-derived sRNAs can target and downregulate the expression of a host gene, in some cases associated with the development of symptoms [22-25, 27]. Our genomewide analysis allowed us to confirm the targeting of 61 genes by vsiRNAs. Interestingly, CMV vsiRNA targets are enriched in photosynthesis-associated genes (exemplified in our proof-of-concept analysis of $R P 1$ downregulation) similar to the previous targeting examples in $N$. benthamiana [27, 51], the predicted targets for CaMV vsiRNAs [80], and the target of a sRNA derived from a chloroplast-replicating viroid [81, 82]. These four virus/viroid-host interactions are associated with the mosaic symptomatology, which affects chlorophyll accumulation. Variegated mutants in Arabidopsis accumulate reactive oxygen species (ROS) [83], which induces cell death [84] and restrict viral infection [85], a, in principle, disadvantageous strategy for viral progression. A recent report indicates that CMV induces autophagy in Arabidopsis and that this response increases both the plant and virus fitness, allowing seed transmission of CMV [86]. vsiRNAs, through the targeting of photosynthesis-associated genes might be a key step in the initiation of anti/proviral autophagy. Alternatively, targeting of photosynthetic factors might be beneficial for the virus by generating a stress response in the plant that accelerates flowering and seed production $[87,88]$ promoting, indirectly, CMV transmission to the next generation.

\section{Conclusions}

Together, our data suggests that vsiRNAs interfere with the endogenous RNA silencing machinery at different levels (Fig. 6): monopolizing the sRNA profile, getting incorporated into all AGO proteins, and targeting endogenous genes. Our results highlight the complex relationship of RNA viruses with the endogenous RNA silencing machinery and the multiple aspects of virus resistance and virulence that this interaction induces.

\section{Methods}

\section{Plant material and viral inoculations}

Two leaves per Col-0 plant in the 4 rosettes leaves stage, 1.04 stage from Boyes et. al 2001 [89] were rub-inoculated with $0.1 \mathrm{M} \mathrm{Na}_{2} \mathrm{HPO}_{4}$ containing the three RNAs that constitutes CMV (strain Fny) genome. These RNAs were previously obtained by in vitro transcription using the MAXIscript T7 Transcription Kit (ThermoFisher) and plasmids containing the individual genomic RNA sequences as the template for the 


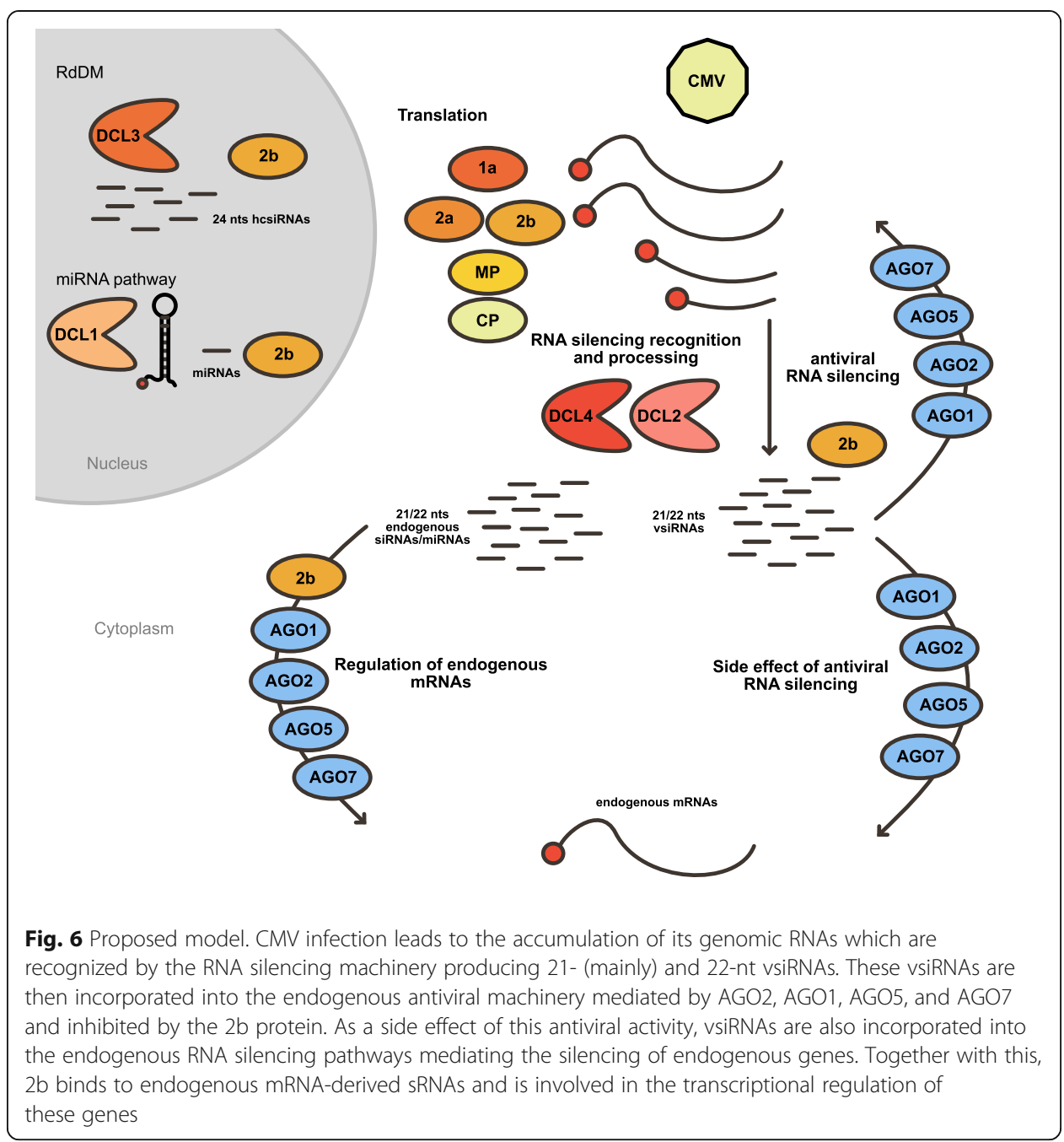

transcription. Mock plants were rub-inoculated with $\mathrm{Na}_{2} \mathrm{HPO}_{4}$ buffer. Rosette leaves from these Col-0 plants were taken at 30 dpi to perform sRNA-seq and PARE-seq. At the same time, $N$. benthamiana plants were infected with the same in vitro transcription products to obtain a reservoir of infected tissue, which was used to infect the ago mutants for RT-qPCR analysis and the Col-0 and AGO7-HA for IP-sRNA-seq. For all the different analysis, samples were taken $30 \mathrm{dpi}$ and plants were grown in the same chamber under the same conditions (long day, $22^{\circ} \mathrm{C}$, and $45 \%$ humidity).

\section{Total RNA, sRNA Northern blot AGO immunoprecipitation, sRNA/PARE library}

\section{construction, and modified 5'RACE}

Total RNA was isolated using TRIzol reagent (Invitrogen). For sRNA Northern blot detection, $20 \mu \mathrm{g}$ of total RNA was loaded in each lane. sRNA gel electrophoresis, blotting, and cross-linking were performed as described in Pall et al. (2008) [90]. Viral genomic RNAs were detected as described in Rio et al. (2015) [91] using the chemical crosslinking strategy described in Pall et al. (2008) [90]. $5 \mu \mathrm{g}$ of total RNA was loaded in each lane. Probes for the detection of + strand viral genomic RNAs were generated using T3 
transcription from the DNA fragments produced using the primers indicated in Additional file 1: Table S6. Probes for the detection of - strand vsiRNAs were generated using T7 transcription from the DNA fragments produced using the primers indicated in Supplementary Table 6 and chemically fragmented as indicated in Martinez (2017) [92]. sRNA libraries were constructed using the NEBNext Small RNA Library Prep Set for Illumina kit (New England Biolabs) following the manufacturer instructions. PARE libraries were constructed following the protocol described in Zhai et al. (2014) using mRNA enriched fractions obtained with the NEB Magnetic mRNA Isolation Kit (New England Biolabs). Modified 5'RACE analysis of vsiRNA cleavage positions was performed as described in Llave et al. (2011) [56] with the primers indicated in Additional file 1: Table S6.

\section{Gene ontology analysis}

Gene ontology (GO) analysis was performed using the GO Term Enrichment tool of The Arabidopsis Information Resource (https://www.arabidopsis.org/tools/bulk/ go/index.jsp).

\section{Gene expression analysis (RT-qPCR)}

Three biological replicates of each treatment (mock and virus-infected), consisting of pools of 3/4 Arabidopsis plants, were used for the gene expression analysis. RNA extraction from these plants was performed using TRIzol Reagent (Invitrogen) following manufacturer instructions. The extracted RNA was treated with DNase I, RNase-free (ThermoFisher Scientific), and cDNA was synthetized using the RevertAid First-Strand cDNA Synthesis Kit (ThermoFisher Scientific) following the manufacturer instructions. Finally, the level of the mRNAs of interested was measured using 5x HOT FIREPol EvaGreen qPCR Mix Plus (ROX) (Solis Biodyne).

\section{Transient expression in Nicotiana benthamiana}

Constructs carrying both the wild-type and the mutated vsRNA-targeted sequences were obtained using the destination vector pB7FWG2.0 (Gateway Cloning), which contains the $35 \mathrm{~S}$ promoter and an N-terminal GFP using the primers listed in Additional file 1: Table S6. The final constructs were transformed into Agrobacterium tumefaciens and agroinfiltrated in both mock and 7 dpi CMV-infected N. benthamiana. Two days after infiltration, GFP fluorescence was visualized using an UV light lamp and samples for gene expression analysis were taken. For this last purpose, three biological replicates consisting of pools of two leaves were sampled for each treatment (mock or CMVinoculated). Protocols were followed as described in the previous section (Gene expression analysis (RT-qPCR)).

\section{AGO and $2 \mathrm{~b}$ immunoprecipitation (IP)-sRNA sequencing}

IPs were performed using AGO1, AGO2, AGO5, HA, and 2b antibodies from Agrisera (references: AS09 527, AS13 2682, AS10 671, AS12 2220, and AS16 3981, respectively) and following the protocol described in McCue et al. (2016) [93]. Then, the total RNA was extracted using TRIzol Reagent (Invitrogen) following the manufacturer instructions and sRNA libraries were prepared using the NEBNext Small RNA Library Prep 
Set for Illumina kit (New Englands Biolabs). Two bioreplicates of each IP and their corresponding input control were generated and analyzed.

\section{Western blot}

First, the total protein was extracted from independent biological replicates of $20 \mathrm{dpi}$ mock-inoculated and CMV-infected rosettes using a standard extraction buffer (100 mM Tris pH $7.5+2 \%$ SDS) and quantified using Pierce Coomassie (Bradford) Protein Assay Kit (ThermoFisher Scientific). Then, $30 \mu \mathrm{g}$ of total protein were run in an SDS-PAGE gel for $2 \mathrm{~h}$ at $120 \mathrm{~V}$ and transfer to a Roti-Fluoro PVDF membrane (ROTH) on a semi-dry transfer for $1 \mathrm{~h}$ at $15 \mathrm{~V}$. The membrane was then blocked for $2 \mathrm{~h}$ on $5 \%$ milk in PBS-T solution at $4^{\circ} \mathrm{C}$. Afterwards, three washes of 5 min with PBS-T were done. The AGO antibodies used were the same ones used for Immunoprecipitation and the actin antibody was also from Agrisera (AS13 2640). The primary antibodies were incubated overnight at $4^{\circ} \mathrm{C}$ in the following dilutions: AGO1, AGO2, and actin 1:10.000 and AGO5: 1:5.000, in $5 \%$ milk in PBS-T. Afterwards, three washes of 5 min with PBS-T were done. Then, the membrane was incubated for $1.5 \mathrm{~h}$ with the secondary antibody (Goat anti-Rabbit IgG (H\&L), HRP conjugated, Agrisera, AS09 602), which was diluted 1:10.000 on 5\% milk in PBS-T, followed by three washes of 5 min with PBS-T. Finally, the Western blot was revealed using the Amersham ECL Prime Western Blotting Detection Reagent (ROTH) following the manufacturer instructions and using a LAS-3000 Imaging System (Fuji). The intensity of the obtained bands was measure using ImageJ blot analysis tools. Then, the intensity of each AGO band was normalized to the intensity of the corresponding actin band. The normalized value was used to calculate the CMV/Mock ratio of protein accumulation. Two bioreplicates of each Western blot were generated and analyzed.

\section{Small RNA and PARE library bioinformatic analysis}

The resulting sequences were de-multiplexed, adapter trimmed, and filtered on length and quality. Two bioreplicates were sequenced for sRNA analysis. sRNAs were matched to the TAIR 10 version of the Arabidopsis genome. Library size was normalized by calculating reads per million of 18-28 nt genome-matched for sRNAs or calculating reads per million for all 19-21-nt genome matched reads for PARE sequencing. sRNA and PARE alignments were performed using bowtie [94] with the following parameters $-t-$ v2 that allows 2 mismatches to the alignments. For sRNA categorization, sRNA libraries were aligned to individual indexes generated for each genomic category. For categorization of sRNAs as mRNA- and intergenic-derived, the sequences matching to miRNAs and TEs, respectively, were subtracted. For PARE library analysis, vsiRNA cleavage events were identified using PARESnip [95]. Identification of high-confidence target sites was performed using astringent PARESnip criteria and considering the presence of such target site in the two bioreplicates. Principal component analysis was performed using the plotPCA tool of deepTools [96] through the Galaxy platform [97]. Two bioreplicates of each sRNA and PARE library were generated and analyzed.

\section{Supplementary Information}

The online version contains supplementary material available at https://doi.org/10.1186/s13059-021-02564-z. 
and CMV-infected sRNA libraries. Table S4. 21-nt TE-derived sRNA accumulation (RPM) in mock and CMV-infected sRNA libraries. Table S5. vsiRNA-targeted genes identified by PARE sequencing. Table S6. Primers used in this study.

Additional file 2: Supplementary figures. Figure S1. Origin of CMV-derived vsiRNAs. Figure S2.

Characterization of endogenous sRNA libraries from mock and CMV-infected tissues. Figure S3. Characterization of TEs producing increased 21-nt sRNAs under CMV infection. Figure S4. AGO antiviral activity and accumulation during CMV infection. Figure S5. Heat map of miRNA accumulation in different AGO-IP sRNA libraries for mock and infected tissues. Figure S6. Characteristics of 2b-IPed sRNAs. Figure S7. Accumulation in different AGOs of vsiRNA targeting mRNAs identified by PARE sequencing. Figure S8. Characteristics of selected vsiRNAs and their targeted genes. Figure S9. Uncropped Northern blot for the detection of CMV genomic RNA1. Figure S10. Uncropped Northern blot for the detection of CMV genomic RNA2. Figure S11. Uncropped Northern blot for the detection of CMV genomic RNA3. Figure S12. Uncropped Northern blot for the detection of vsiRNAs derived from CMV genomic RNA1 Figure S13. Uncropped Northern blot for the detection of vsiRNAs derived from CMV genomic RNA2. Figure S14. Uncropped Northern blot for the detection of vsiRNAs derived from CMV genomic RNA3. Figure S15. Uncropped Northern blot for the detection of miR168. Figure S16. Uncropped Northern blot for the detection of the snRNA U6. Figure S17. Uncropped ethidium bromide-stained agarose gel used as loading control for the detection of CMV genomic RNAs. Figure S18. Uncropped ethidium bromide-stained agarose gel used for the analysis and cloning of 5'RACE fragments derived from AT4G21210. Figure S19. Uncropped Western blot gels used in the detection and quantification of $\mathrm{AGO}$ and Actin proteins.

Additional file 3. Review history.

\section{Acknowledgements}

The authors thank Dr. Montserrat Martin and Prof. Peter Palukaitis for providing CMV-Fny cDNA clones and Prof. Vicente Pallas, Dr. Gustavo Gomez, and Joan Marquez-Molins for providing feedback to the draft version of this manuscript.

\section{Peer review information}

Kevin Pang was the primary editor of this article and managed its editorial process and peer review in collaboration with the rest of the editorial team.

\section{Review history}

The review history is available as Additional file 3.

\section{Authors' informations}

Twitter handles: @marialuzal (Maria Luz Annacondia); @germarar_80 (German Martinez).

\section{Authors' contributions}

MLA and GM designed the experiments. MLA performed the experiments and generated high-throughput libraries. GM analyzed the bioinformatic data. MLA and GM wrote the manuscript. The authors read and approved the final manuscript.

\section{Funding}

We thank SLU, the Carl Tryggers Foundation (CTS 18:251), the Swedish Research Council (VR 2016-05410), and the Knut and Alice Wallenberg Foundation (KAW 2019.0062) for supporting research in the Martinez group. Sequencing was performed by Fasteris SA (Switzerland). Open Access funding provided by Swedish University of Agricultural Sciences.

\section{Availability of data and materials}

All raw and processed sequencing data generated in this study have been submitted to the NCBI Gene Expression Omnibus (GSE169677) [98].

\section{Declarations}

Ethics approval and consent to participate

Not applicable.

\section{Consent for publication}

Not applicable.

\section{Competing interests}

The authors declare that they have no competing interests.

Received: 26 April 2021 Accepted: 2 December 2021

Published online: 15 December 2021

\section{References}

1. Dowen RH, Pelizzola M, Schmitz RJ, Lister R, Dowen JM, Nery JR, et al. Widespread dynamic DNA methylation in response to biotic stress. Proc Natl Acad Sci U S A. 2012;109(32):E2183-91. https://doi.org/10.1073/pnas.1209329109.

2. Berr A, Menard R, Heitz T, Shen WH. Chromatin modification and remodelling: a regulatory landscape for the control of Arabidopsis defence responses upon pathogen attack. Cell Microbiol. 2012;14(6):829-39. https://doi.org/10.1111/j.14625822.2012.01785.x. 
3. Kim JM, Sasaki T, Ueda M, Sako K, Seki M. Chromatin changes in response to drought, salinity, heat, and cold stresses in plants. Front Plant Sci. 2015;6:114. https://doi.org/10.3389/fpls.2015.00114.

4. Garcia-Ruiz H, Carbonell A, Hoyer JS, Fahlgren N, Gilbert KB, Takeda A, et al. Roles and programming of Arabidopsis ARGONAUTE proteins during Turnip mosaic virus infection. PLoS Pathog. 2015;11(3):e1004755. https://doi.org/10.1371/ journal.ppat.1004755

5. Baulcombe D. RNA silencing in plants. Nature. 2004:431(7006):356-63. https://doi.org/10.1038/nature02874.

6. Li F, Wang A. RNA-targeted antiviral immunity: more than just RNA silencing. Trends Microbiol. 2019;27(9):792-805. https://doi.org/10.1016/j.tim.2019.05.007.

7. Allen E, Xie Z, Gustafson AM, Carrington JC. microRNA-directed phasing during trans-acting siRNA biogenesis in plants. Cell. 2005;121(2):207-21. https://doi.org/10.1016/j.cell.2005.04.004.

8. Medina-Puche L, Lozano-Duran R. Tailoring the cell: a glimpse of how plant viruses manipulate their hosts. Curr Opin Plant Biol. 2019;52:164-73. https://doi.org/10.1016/j.pbi.2019.09.007.

9. Pumplin N, Voinnet O. RNA silencing suppression by plant pathogens: defence, counter-defence and counter-counterdefence. Nat Rev Microbiol. 2013;11(11):745-60. https://doi.org/10.1038/nrmicro3120.

10. Ding SW, Li H, Lu R, Li F, Li WX. RNA silencing: a conserved antiviral immunity of plants and animals. Virus Res. 2004; 102(1):109-15. https://doi.org/10.1016/j.virusres.2004.01.021.

11. Qu F, Ye X, Morris TJ. Arabidopsis DRB4, AGO1, AGO7, and RDR6 participate in a DCL4-initiated antiviral RNA silencing pathway negatively regulated by DCL1. Proc Natl Acad Sci U S A. 2008;105(38):14732-7. https://doi.org/10.1073/pnas. 0805760105.

12. Qin C, Li B, Fan Y, Zhang X, Yu Z, Ryabov E, et al. Roles of Dicer-like proteins 2 and 4 in intra- and intercellular antiviral silencing. Plant Physiol. 2017;174(2):1067-81. https://doi.org/10.1104/pp.17.00475.

13. Deleris A, Gallego-Bartolome J, Bao J, Kasschau KD, Carrington JC, Voinnet O. Hierarchical action and inhibition of plant Dicer-like proteins in antiviral defense. Science. 2006;313(5783):68-71. https://doi.org/10.1126/science.1128214.

14. Wang XB, Jovel J, Udomporn P, Wang Y, Wu Q, Li WX, et al. The 21-nucleotide, but not 22-nucleotide, viral secondary small interfering RNAs direct potent antiviral defense by two cooperative argonautes in Arabidopsis thaliana. Plant Cell. 2011;23(4):1625-38. https://doi.org/10.1105/tpc.110.082305.

15. Csorba T, Kontra L, Burgyan J. Viral silencing suppressors: tools forged to fine-tune host-pathogen coexistence. Virology. 2015:479-480:85-103. https://doi.org/10.1016/j.virol.2015.02.028.

16. Diaz-Pendon JA, Ding SW. Direct and indirect roles of viral suppressors of RNA silencing in pathogenesis. Annu Rev Phytopathol. 2008;46(1):303-26. https://doi.org/10.1146/annurev.phyto.46.081407.104746.

17. Daros JA. Viral suppressors: combatting RNA silencing. Nat Plants. 2017;3(7):17098. https://doi.org/10.1038/nplants.2017. 98.

18. Silhavy D, Molnár A, Lucioli A, Szittya G, Hornyik C, Tavazza M, et al. A viral protein suppresses RNA silencing and binds silencing-generated, 21- to 25-nucleotide double-stranded RNAs. EMBO J. 2002;21(12):3070-80. https://doi.org/10.1093/ emboj/cdf312.

19. Burgyan J, Havelda Z. Viral suppressors of RNA silencing. Trends Plant Sci. 2011;16(5):265-72. https://doi.org/10.1016/j. tplants.2011.02.010

20. Hamera S, Song X, Su L, Chen X, Fang R. Cucumber mosaic virus suppressor 2b binds to AGO4-related small RNAs and impairs AGO4 activities. Plant J. 2012;69(1):104-15. https://doi.org/10.1111/j.1365-313X.2011.04774.X.

21. Zhang X, Yuan YR, Pei Y, Lin SS, Tuschl T, Patel DJ, et al. Cucumber mosaic virus-encoded 2b suppressor inhibits Arabidopsis Argonaute1 cleavage activity to counter plant defense. Genes Dev. 2006;20(23):3255-68. https://doi.org/1 $0.1101 /$ gad.1495506.

22. Shahid S, Kim G, Johnson NR, Wafula E, Wang F, Coruh C, et al. MicroRNAs from the parasitic plant Cuscuta campestris target host messenger RNAs. Nature. 2018;553(7686):82-5. https://doi.org/10.1038/nature25027.

23. Weiberg A, Wang M, Lin F-M, Zhao H, Zhang Z, Kaloshian I, et al. Fungal small RNAs suppress plant immunity by hijacking host RNA interference pathways. Science. 2013;342(6154):118-1123. https://doi.org/10.1126/science.1239705.

24. Shimura H, Pantaleo V, Ishihara T, Myojo N, Inaba J, Sueda K, et al. A viral satellite RNA induces yellow symptoms on tobacco by targeting a gene involved in chlorophyll biosynthesis using the RNA silencing machinery. PLoS Pathog. 2011;7(5):e1002021. https://doi.org/10.1371/journal.ppat.1002021.

25. Adkar-Purushothama CR, Brosseau C, Giguere T, Sano T, Moffett P, Perreault JP. Small RNA derived from the virulence modulating region of the potato spindle tuber viroid silences callose synthase genes of tomato plants. Plant Cell. 2015; 27(8):2178-94. https://doi.org/10.1105/tpc.15.00523.

26. McCue AD, Nuthikattu S, Slotkin RK. Genome-wide identification of genes regulated in trans by transposable element small interfering RNAs. RNA Biol. 2013;10(8):1379-95. https://doi.org/10.4161/rna.25555.

27. Smith NA, Eamens AL, Wang MB. Viral small interfering RNAs target host genes to mediate disease symptoms in plants. PLoS Pathog. 2011;7(5):e1002022. https://doi.org/10.1371/journal.ppat.1002022.

28. Navarro B, Gisel A, Rodio ME, Delgado S, Flores R, Di Serio F. Small RNAs containing the pathogenic determinant of a chloroplast-replicating viroid guide the degradation of a host mRNA as predicted by RNA silencing. Plant J. 2012;70(6): 991-1003. https://doi.org/10.1111/j.1365-313X.2012.04940.x.

29. Donaire L, Wang Y, Gonzalez-lbeas D, Mayer KF, Aranda MA, Llave C. Deep-sequencing of plant viral small RNAs reveals effective and widespread targeting of viral genomes. Virology. 2009;392(2):203-14. https://doi.org/10.1016/j.virol.2009.07.005.

30. Diaz-Pendon JA, Li F, Li WX, Ding SW. Suppression of antiviral silencing by cucumber mosaic virus $2 \mathrm{~b}$ protein in Arabidopsis is associated with drastically reduced accumulation of three classes of viral small interfering RNAs. Plant Cell. 2007;19(6):2053-63. https://doi.org/10.1105/tpc.106.047449.

31. Herranz MC, Navarro JA, Sommen E, Pallas V. Comparative analysis among the small RNA populations of source, sink and conductive tissues in two different plant-virus pathosystems. BMC Genomics. 2015;16(1):117. https://doi.org/10.11 86/s12864-015-1327-5.

32. Vaistij FE, Jones L. Compromised virus-induced gene silencing in RDR6-deficient plants. Plant Physiol. 2009;149(3):1399407. https://doi.org/10.1104/pp.108.132688.

33. Wang XB, Wu Q, Ito T, Cillo F, Li WX, Chen X, et al. RNAi-mediated viral immunity requires amplification of virus-derived siRNAs in Arabidopsis thaliana. Proc Natl Acad Sci U S A. 2010;107(1):484-9. https://doi.org/10.1073/pnas.0904086107. 
34. Varallyay E, Valoczi A, Agyi A, Burgyan J, Havelda Z. Plant virus-mediated induction of miR168 is associated with repression of ARGONAUTE1 accumulation. EMBO J. 2010;29(20):3507-19. https://doi.org/10.1038/emboj.2010.215.

35. Pereira V. Insertion bias and purifying selection of retrotransposons in the Arabidopsis thaliana genome. Genome Biol. 2004;5(10):R79. https://doi.org/10.1186/gb-2004-5-10-r79.

36. Cao M, Du P, Wang X, Yu YQ, Qiu YH, Li W, et al. Virus infection triggers widespread silencing of host genes by a distinct class of endogenous siRNAs in Arabidopsis. Proc Natl Acad Sci U S A. 2014;111(40):14613-8. https://doi.org/10.1 073/pnas.1407131111.

37. Mi S, Cai T, Hu Y, Chen Y, Hodges E, Ni F, et al. Sorting of small RNAs into Arabidopsis argonaute complexes is directed by the $5^{\prime}$ terminal nucleotide. Cell. 2008;133(1):116-27. https://doi.org/10.1016/j.cell.2008.02.034.

38. Harvey JJ, Lewsey MG, Patel K, Westwood J, Heimstadt S, Carr JP, et al. An antiviral defense role of AGO2 in plants. PLoS One. 2011;6(1):e14639. https://doi.org/10.1371/journal.pone.0014639.

39. Brosseau C, Moffett P. Functional and genetic analysis identify a role for arabidopsis ARGONAUTE5 in antiviral RNA silencing. Plant Cell. 2015;27(6):1742-54. https://doi.org/10.1105/tpc.15.00264.

40. Carbonell A, Fahlgren N, Garcia-Ruiz H, Gilbert KB, Montgomery TA, Nguyen T, et al. Functional analysis of three Arabidopsis ARGONAUTES using slicer-defective mutants. Plant Cell. 2012;24(9):3613-29. https://doi.org/10.1105/tpc.112.099945.

41. Lewsey M, Robertson FC, Canto T, Palukaitis P, Carr JP. Selective targeting of miRNA-regulated plant development by a viral counter-silencing protein. Plant J. 2007;50(2):240-52. https://doi.org/10.1111/j.1365-313X.2007.03042.x.

42. Hamera S, Yan Y, Song X, Chaudhary SU, Murtaza I, Su L, et al. Expression of cucumber mosaic virus suppressor $2 b$ alters FWA methylation and its siRNA accumulation in Arabidopsis thaliana. Biol Open. 2016;5(11):1727-34. https//doi.org/10.1242/bio.017244.

43. Du ZY, Chen AZ, Chen WH, Westwood JH, Baulcombe DC, Carr JP. Using a viral vector to reveal the role of microRNA159 in disease symptom induction by a severe strain of cucumber mosaic virus. Plant Physiol. 2014;164(3): 1378-88. https://doi.org/10.1104/pp.113.232090.

44. Duan CG, Fang YY, Zhou BJ, Zhao JH, Hou WN, Zhu H, et al. Suppression of Arabidopsis ARGONAUTE1-mediated slicing, transgene-induced RNA silencing, and DNA methylation by distinct domains of the Cucumber mosaic virus $2 \mathrm{~b}$ protein. Plant Cell. 2012;24(1):259-74. https://doi.org/10.1105/tpc.111.092718.

45. Tian A, Miyashita S, Ando S, Takahashi H. Single amino acid substitutions in the cucumber mosaic virus 1a protein induce necrotic cell death in virus-inoculated leaves without affecting virus multiplication. Viruses-Basel. 2020;12(1). https://doi.org/10.3390/v12010091.

46. Zhao JH, Liu XL, Fang YY, Fang RX, Guo HS. CMV2b-dependent regulation of host defense pathways in the context of viral infection. Viruses. 2018;10(11). https://doi.org/10.3390/v10110618.

47. Folkes L, Moxon S, Woolfenden HC, Stocks MB, Szittya G, Dalmay T, et al. PAREsnip: a tool for rapid genome-wide discovery of small RNA/target interactions evidenced through degradome sequencing. Nucleic Acids Res. 2012;40(13): e103. https://doi.org/10.1093/nar/gks277.

48. Pietrzykowska M, Suorsa M, Semchonok DA, Tikkanen M, Boekema EJ, Aro EM, et al. The light-harvesting chlorophyll a/b binding proteins Lhcb1 and Lhcb2 play complementary roles during state transitions in Arabidopsis. Plant Cell. 2014; 26(9):3646-60. https://doi.org/10.1105/tpc.114.127373.

49. Gonzalez-Cabanelas D, Wright LP, Paetz C, Onkokesung N, Gershenzon J, Rodriguez-Concepcion M, et al. The diversion of 2-C-methyl-D-erythritol-2,4-cyclodiphosphate from the 2-C-methyl-D-erythritol 4-phosphate pathway to hemiterpene glycosides mediates stress responses in Arabidopsis thaliana. Plant J. 2015;82(1):122-37. https://doi. org/10.1111/tpj.12798.

50. Qu J, Kang SG, Wang W, Musier-Forsyth K, Jang JC. The Arabidopsis thaliana tandem zinc finger 1 (AtTZF1) protein in RNA binding and decay. Plant J. 2014;78(3):452-67. https://doi.org/10.1111/tpj.12485.

51. Shimura H, Pantaleo V, Ishihara T, Myojo N, J-i I, Sueda K, et al. A viral satellite RNA induces yellow symptoms on tobacco by targeting a gene involved in chlorophyll biosynthesis using the RNA silencing machinery. PLOS Pathogens. 2011;7(5):e1002021. https://doi.org/10.1371/journal.ppat.1002021.

52. Carbonell A. Secondary small interfering RNA-based silencing tools in plants: an update. Front Plant Sci. 2019;10:687. https://doi.org/10.3389/fpls.2019.00687.

53. Astley HM, Parsley K, Aubry S, Chastain CJ, Burnell JN, Webb ME, et al. The pyruvate, orthophosphate dikinase regulatory proteins of Arabidopsis are both bifunctional and interact with the catalytic and nucleotide-binding domains of pyruvate, orthophosphate dikinase. Plant J. 2011;68(6):1070-80. https://doi.org/10.1111/j.1365-313X.2011.04759.x.

54. Chastain CJ, Xu W, Parsley K, Sarath G, Hibberd JM, Chollet R. The pyruvate, orthophosphate dikinase regulatory proteins of Arabidopsis possess a novel, unprecedented Ser/Thr protein kinase primary structure. Plant J. 2008;53(5):854-63. https://doi.org/10.1111/j.1365-313X.2007.03366.X.

55. Liu Q, Wang F, Axtell MJ. Analysis of complementarity requirements for plant microRNA targeting using a Nicotiana benthamiana quantitative transient assay. Plant Cell. 2014;26(2):741-53. https://doi.org/10.1105/tpc.113.120972.

56. Llave C, Franco-Zorrilla JM, Solano R, Barajas D. Target validation of plant microRNAs. Methods Mol Biol. 2011;732:187208. https://doi.org/10.1007/978-1-61779-083-6 14

57. Szittya G, Burgyan J. RNA interference-mediated intrinsic antiviral immunity in plants. Curr Top Microbiol Immunol. 2013; 371:153-81. https://doi.org/10.1007/978-3-642-37765-5_6.

58. Lindbo JA, Dougherty WG. Untranslatable transcripts of the tobacco etch virus coat protein gene sequence can interfere with tobacco etch virus replication in transgenic plants and protoplasts. Virology. 1992;189(2):725-33. https:// doi.org/10.1016/0042-6822(92)90595-G.

59. Lindbo JA, Silva-Rosales L, Proebsting WM, Dougherty WG. Induction of a highly specific antiviral state in transgenic plants: implications for regulation of gene expression and virus resistance. Plant Cell. 1993;5(12):1749-59. https://doi. org/10.2307/3869691.

60. Qiu Y, Wu Y, Zhang Y, Xu W, Wang C, Zhu S. Profiling of small RNAs derived from cucumber mosaic virus in infected Nicotiana benthamiana plants by deep sequencing. Virus Res. 2018;252:1-7. https://doi.org/10.1016/j.virusres.2018.05.013.

61. Fang $Y Y$, Smith NA, Zhao JH, Lee JR, Guo HS, Wang MB. Cloning and profiling of small RNAs from cucumber mosaic virus satellite RNA. Methods Mol Biol. 2015;1236:99-109. https://doi.org/10.1007/978-1-4939-1743-3_9.

62. Du Q-S, Duan C-G, Zhang Z-H, Fang $Y-Y$, Fang R-X, Xie Q, et al. DCL4 targets cucumber mosaic virus satellite RNA at novel secondary structures. J Virol. 2007;81(17):9142-51. https://doi.org/10.1128/JVI.02885-06. 
63. Martinez G, Donaire L, Llave C, Pallas V, Gomez G. High-throughput sequencing of Hop stunt viroid-derived small RNAs from cucumber leaves and phloem. Mol Plant Pathol. 2010;11(3):347-59. https://doi.org/10.1111/j.1364-3703.2009.00608.X.

64. Di Serio F, Gisel A, Navarro B, Delgado S, Martínez de Alba Á-E, Donvito G, et al. Deep sequencing of the small RNAs derived from two symptomatic variants of a chloroplastic viroid: implications for their genesis and for pathogenesis. PLoS ONE. 2009;4(10):e7539. https://doi.org/10.1371/journal.pone.0007539.

65. Owen J, Shintaku M, Aeschleman P, Ben Tahar S, Palukaitis P. Nucleotide sequence and evolutionary relationships of cucumber mosaic virus (CMV) strains: CMV RNA 3. J Gen Virol. 1990;71(Pt 10):2243-9. https://doi.org/10.1099/0022-131771-10-2243.

66. Rizzo TM, Palukaitis P. Nucleotide sequence and evolutionary relationships of cucumber mosaic virus (CMV) strains: CMV RNA 1. J Gen Virol. 1989;70(Pt 1):1-11. https://doi.org/10.1099/0022-1317-70-1-1.

67. Rizzo TM, Palukaitis P. Nucleotide sequence and evolutionary relationships of cucumber mosaic virus (CMV) strains: CMV RNA 2. J Gen Virol. 1988;69(Pt 8):1777-87. https://doi.org/10.1099/0022-1317-69-8-1777.

68. Tromas N, Zwart MP, Lafforgue G, Elena SF. Within-host spatiotemporal dynamics of plant virus infection at the cellular level. Plos Genet. 2014;10(2):e1004186. https://doi.org/10.1371/journal.pgen.1004186.

69. Gonzalez-Jara P, Fraile A, Canto T, Garcia-Arenal F. The multiplicity of infection of a plant virus varies during colonization of its eukaryotic host. J Virol. 2009;83(15):7487-94. https://doi.org/10.1128/JVI.00636-09.

70. Gutierrez S, Pirolles E, Yvon M, Baecker V, Michalakis Y, Blanc S. The multiplicity of cellular infection changes depending on the route of cell infection in a plant virus. J Virol. 2015;89(18):9665-75. https://doi.org/10.1128/JVI.00537-15.

71. Rosas-Diaz T, Zhang D, Fan P, Wang L, Ding X, Jiang Y, et al. A virus-targeted plant receptor-like kinase promotes cell-tocell spread of RNAi. Proc Natl Acad Sci U S A. 2018;115(6):1388-93. https://doi.org/10.1073/pnas.1715556115.

72. Incarbone M, Zimmermann A, Hammann P, Erhardt M, Michel F, Dunoyer P. Neutralization of mobile antiviral small RNA through peroxisomal import. Nat Plants. 2017;3(7):17094. https://doi.org/10.1038/nplants.2017.94.

73. Minoia S, Carbonell A, Di Serio F, Gisel A, Carrington JC, Navarro B, et al. Specific argonautes selectively bind small RNAs derived from potato spindle tuber viroid and attenuate viroid accumulation in vivo. J Virol. 2014;88(20):11933-45. https://doi.org/10.1128/JVI.01404-14.

74. Ando S, Jaskiewicz M, Mochizuki S, Koseki S, Miyashita S, Takahashi H, et al. Priming for enhanced ARGONAUTE2 activation accompanies induced resistance to cucumber mosaic virus in Arabidopsis thaliana. Mol Plant Pathol. 2021; 22(1):19-30. https://doi.org/10.1111/mpp.13005.

75. Erdmann RM, Picard CL. RNA-directed DNA methylation. PLoS Genet. 2020;16(10):e1009034. https://doi.org/10.1371/ journal.pgen.1009034.

76. Wang C, Wang C, Xu W, Zou J, Qiu Y, Kong J, et al. Epigenetic changes in the regulation of nicotiana tabacum response to cucumber mosaic virus infection and symptom recovery through single-base resolution methylomes. Viruses. 2018; 10(8):402. https://doi.org/10.3390/v10080402.

77. Li S, Castillo-Gonzalez C, Yu B, Zhang X. The functions of plant small RNAs in development and in stress responses. Plant J. 2017;90(4):654-70. https://doi.org/10.1111/tpj.13444.

78. Podkaminski D, Vogel J. Small RNAs promote mRNA stability to activate the synthesis of virulence factors. Mol Microbiol. 2010;78(6):1327-31. https://doi.org/10.1111/j.1365-2958.2010.07428.x.

79. Brodersen P, Sakvarelidze-Achard L, Bruun-Rasmussen M, Dunoyer P, Yamamoto YY, Sieburth L, et al. Widespread translational inhibition by plant miRNAs and siRNAs. Science. 2008;320(5880):1185-90. https://doi.org/10.1126/science.1159151.

80. Leonetti P, Ghasemzadeh A, Consiglio A, Gursinsky T, Behrens S-E, Pantaleo V. Endogenous activated small interfering RNAs in virus-infected Brassicaceae crops show a common host gene-silencing pattern affecting photosynthesis and stress response. New Phytologist. 2021;229(3):1650-64. https://doi.org/10.1111/nph.16932.

81. Delgado S, Navarro B, Serra P, Gentit P, Cambra MA, Chiumenti M, et al. How sequence variants of a plastid-replicating viroid with one single nucleotide change initiate disease in its natural host. Rna Biol. 2019;16(7):906-17. https://doi.org/1 0.1080/15476286.2019.1600396.

82. Rodio ME, Delgado S, De Stradis A, Gomez MD, Flores R, Di Serio F. A viroid RNA with a specific structural motif inhibits chloroplast development. Plant Cell. 2007;19(11):3610-26. https://doi.org/10.1105/tpc.106.049775.

83. Kato Y, Miura E, Ido K, Ifuku K, Sakamoto W. The variegated mutants lacking chloroplastic FtsHs are defective in D1 degradation and accumulate reactive oxygen species. Plant Physiol. 2009;151(4):1790-801. https://doi.org/10.1104/pp.109.146589.

84. Van Breusegem F, Dat JF. Reactive oxygen species in plant cell death. Plant Physiol. 2006;141(2):384-90. https://doi.org/1 0.1104/pp.106.078295.

85. Yang M, Ismayil A, Liu YL. Autophagy in plant-virus interactions. Ann Rev Virol. 2020;7:403-19.

86. Shukla A, Hoffmann G, López-González S, Hofius D, Hafrén A. Salicylic acid and the viral virulence factor $2 b$ regulate the divergent roles of autophagy during cucumber mosaic virus infection. Autophagy. 2021:1-13. https://doi.org/10.1080/1 5548627.2021.1987674.

87. Wang J, Leister D, Bolle C. Photosynthetic lesions can trigger accelerated senescence in Arabidopsis thaliana. J Exp Botany. 2015:66(21):6891-903. https://doi.org/10.1093/jxb/erv393.

88. Reig-Valiente JL, Borreda C, Talon M, Domingo C. The G123 rice mutant, carrying a mutation in SE13, presents alterations in the expression patterns of photosynthetic and major flowering regulatory genes. Plos One. 2020;15(5): e0233120. https://doi.org/10.1371/journal.pone.0233120.

89. Boyes DC, Zayed AM, Ascenzi R, McCaskill AJ, Hoffman NE, Davis KR, et al. Growth-stage phenotypic analysis of Arabidopsis, a model for high throughput functional genomics in plants. Plant Cell. 2001;13(7):1499-510. https://doi. org/10.1105/TPC.010011.

90. Pall GS, Hamilton AJ. Improved northern blot method for enhanced detection of small RNA. Nat Protoc. 2008;3(6):107784. https://doi.org/10.1038/nprot.2008.67.

91. Rio DC. Northern blots: capillary transfer of RNA from agarose gels and filter hybridization using standard stringency conditions. Cold Spring Harb Protoc. 2015;2015(3):306-13. https://doi.org/10.1101/pdb.prot081018.

92. Martinez G. Isolation and detection of small RNAs from pollen. Methods Mol Biol. 2017;1669:237-50. https://doi.org/10.1 007/978-1-4939-7286-9_19.

93. McCue AD, Nuthikattu S, Reeder SH, Slotkin RK. Gene expression and stress response mediated by the epigenetic regulation of a transposable element small RNA. PLoS Genet. 2012;8(2):e1002474. https://doi.org/10.1371/journal.pgen.1002474. 
94. Langmead B, Trapnell C, Pop M, Salzberg SL. Ultrafast and memory-efficient alignment of short DNA sequences to the human genome. Genome Biol. 2009;10(3):R25. https://doi.org/10.1186/gb-2009-10-3-r25.

95. Stocks MB, Mohorianu I, Beckers M, Paicu C, Moxon S, Thody J, et al. The UEA sRNA Workbench (version 4.4): a comprehensive suite of tools for analyzing miRNAs and sRNAs. Bioinformatics. 2018;34(19):3382-4. https://doi.org/10.1 093/bioinformatics/bty338.

96. Ramirez F, Ryan DP, Gruning B, Bhardwaj V, Kilpert F, Richter AS, et al. deepTools2: a next generation web server for deep-sequencing data analysis. Nucleic Acids Res. 2016;44(W1):W160-5. https://doi.org/10.1093/nar/gkw257.

97. Afgan E, Baker D, Batut B, van den Beek M, Bouvier D, Cech M, et al. The Galaxy platform for accessible, reproducible and collaborative biomedical analyses: 2018 update. Nucleic Acids Res. 2018;46(W1):W537-44. https://doi.org/10.1093/na r/gky379.

98. Annacondia M, Martinez G. Reprogramming of RNA silencing triggered by cucumber mosaic virus infection in Arabidopsis. Gene Expr Omnibus. https://www.ncbi.nlm.nih.gov/geo/query/acc.cgi?acc=GSE169677. 2021. Accessed 1 Dec 2021.

\section{Publisher's Note}

Springer Nature remains neutral with regard to jurisdictional claims in published maps and institutional affiliations.

- fast, convenient online submission

- thorough peer review by experienced researchers in your field

- rapid publication on acceptance

- support for research data, including large and complex data types

- gold Open Access which fosters wider collaboration and increased citations

- maximum visibility for your research: over $100 \mathrm{M}$ website views per year

At $\mathrm{BMC}$, research is always in progress. 